\title{
Proceeding
}

Supplementary Issue: Autumn Conferences of Sports Science. Costa Blanca Sports Science Events, 18-19 December 2020. Alicante, Spain.

\section{Effects of Cornus mas extract combined with aerobic and resistance exercise on blood metabolic parameters and liver enzymes of obese rats}

\author{
SARA TORKAMANEH ${ }^{1}$, ANGEL SAEZ-BERLANGA 1 , FERNANDO MARTIN1, PEDRO GARGALLO1, \\ JORGE FLANDEZ2 ${ }^{2}$, JAVIER GENE-MORALES ${ }^{1,3}$, MAHMOUD RAFIEIAN-KOPAEI $^{4} \triangle$, JUAN CARLOS \\ COLADO1,5 \\ ${ }^{1}$ Research Unit in Sport and Health, University of Valencia, Valencia, Spain \\ 2Institute of Education Sciences, Austral University of Chile, Ciudad de Valdivia, Chile \\ 3 Institute on Traffic and Road Safety (INTRAS), University of Valencia, Valencia, Spain \\ 4Medical Plants Research Center, Shahrekord University of Medical Sciences, Sharekord, Islamic Republic of Iran \\ ${ }^{5}$ Department of Physical Education and Sports, University of Valencia, Valencia, Spain
}

\begin{abstract}
Purpose: The purpose was to investigate the effects of six weeks of resistance or aerobic exercise combined with the intake of Cornus mas extract on the lipid profile, metabolic parameters, and liver enzymes of obese rats. Methods: 49 male Wistar rats were divided into seven groups: 1) healthy control $(n=7) ; 2)$ hypercaloric fatty-food-based diet $(n=7)$; 3) aerobic exercise $(A E, n=7) ; 4)$ resistance exercise $(R E, n=7) ; 5)$ Cornus mas extract intake $(C, n=7) ; 6)$ Cornus mas combined with aerobic exercise (CAE, $n=7)$; and 7) Cornus mas combined with resistance exercise (CRE, $n=7)$. All the rats (except the controls) were induced fatty liver by six weeks of a hypercaloric diet before the intervention. After the six-week intervention, blood samples were taken to obtain levels of triglycerides, high-density lipoprotein cholesterol (HDL), lowdensity lipoprotein cholesterol (LDL), cholesterol, glucose, c-reactive protein (CRP), alanine aminotransferase (ALT), aspartate aminotransferase (AST), creatinine, and urea. A one-way ANOVA or the Kruskal Wallis tests for the non-normally distributed variables, with post-hoc pairwise comparisons, assessed differences between groups. Results: All the intervention groups significantly $(p<.05)$ improved the parameters compared to the hypercaloric group in almost all the assessed parameters, reaching in many cases significantly better values than the healthy group (control). Adding the Cornus supplementation to the exercise resulted in slightly non-significant better values. Conclusion: Cornus mas extract and aerobic or resistance training may be helpful to treat fatty liver and also reduce the lipid profile levels.
\end{abstract}

Keywords: Aerobic; Resistance training; Physical activity; Fatty liver; Cardiovascular disease; Wistar rats.

\section{Cite this article as:}

Torkamaneh, S., Saez-Berlanga, A., Martín, F., Gargallo, P., Flández, J., Gene-Morales, J., Rafieian-Kopaei, M., \& Colado, J.C. (2021). Effects of Cornus mas extract combined with aerobic and resistance exercise on blood metabolic parameters and liver enzymes of obese rats. Journal of Human Sport and Exercise, 16(2proc), S630-S639. doi:https://doi.org/10.14198/ihse.2021.16.Proc2.48

Corresponding author. Medical Plants Research Centre, Basic Health Science Institute, Shahrekord University of Medical Science. 8813833435, Sharekord, Islamic Republic of Iran. https://orcid.org/0000-0002-1860-1141

E-mail: rafieian@skums.ac.ir

Abstract submitted to: Autumn Conferences of Sports Science. Costa Blanca Sports Science Events, 18-19 December 2020. Alicante, Spain.

JOURNAL OF HUMAN SPORT \& EXERCISE ISSN 1988-5202

(c) Faculty of Education. University of Alicante

doi:10.14198/jhse.2021.16.Proc2.48 


\section{INTRODUCTION}

The concurrent epidemic of metabolic diseases such as obesity, type 2 diabetes, and non-alcoholic fatty liver disease (NAFLD) has been increasing in both developed and developing countries (El Hadi et al., 2019; Tomeno et al., 2020), being a major risk factor for cardiovascular disease (CVD) (Ismaiel et al., 2019). According to the World Health Organization, CVD is the cause of 18 million deaths per year.

NAFLD is the most common liver disease (lloon Kashkooli et al., 2015) and is a key risk factor for CVD and diabetes type 2 (Della Pepa et al., 2017). NAFLD refers to a range of liver diseases caused by abnormal fatty deposits in the liver and a comprehensive spectrum of histological liver abnormalities ranging from simple triglyceride accumulation in hepatocytes to non-alcoholic fatty liver (NAFL) and non-alcoholic steatohepatitis (NASH; Tomeno et al., 2020). Furthermore, NAFLD can lead to death if it progresses to cirrhosis and/or hepatocellular carcinoma (liver cell cancer; Reid, 2006). Previous studies show that liver enzyme levels such as alanine aminotransferase (ALT) and aspartate aminotransferase (AST), formerly called serum glutamic pyruvic transaminase (GPT) and serum glutamic oxaloacetic transaminase (GOT), respectively (Huang et al., 2006), are some readily available factors (perhaps the best) for assessing liver status (Yıldırım et al., 2010). In this sense, the increase in ALT levels a common symptom of advanced fatty liver disease or hepatic steatosis in 80 to 90 percent of cases. ALT increases are associated with inflammation caused by fat accumulation in the liver, abdominal obesity, metabolic syndrome, dyslipidemia, hyperglycemia, hypertension, high blood pressure, and type 2 diabetes (Hallsworth et al., 2011). Determining the most appropriate treatment for NAFLD is very important due to its increasing trend and the financial, individual, and social burden of this disease.

Exercise is an important part of the overall approach to treating fatty liver disease. In many obese individuals, weight loss can be achieved through increased physical activity (Stevanović et al., 2020). Lipid profile is characterized by an increase in triglycerides and a decrease in high-density lipoprotein (HDL) levels, which is associated with other metabolic risk factors, including abdominal obesity and insulin resistance (a major cause of fatty liver) (Lehto et al., 1997). Aerobic exercise, due to the lipolysis processes involved in aerobic energy supply, reduces plasma triglycerides and increases HDL (Thompson \& Rader, 2001), which is a good way to reduce liver fat and improve liver damage indicators in patients with NAFLD (Yavari et al., 2012). Based on their experiments, researchers have reported a significant inverse relationship between fitness and cardio-respiratory scores and liver fat in NAFLD patients (Nikroo et al., 2011; Zelber-Sagi et al., 2011). Resistance training can improve muscle mass, strength, and power; increase insulin sensitivity and daily energy expenditure (Dunstan et al., 2002); therefore, it is used as a health-promoting tool in the elderly and obese.

Recently, much thought has been given to the role of natural products in the treatment of various diseases such as diabetes, different microbial strains, inflammation, oxidative stress, and also cancer. Besides physical exercise for weight loss and treatment of fatty liver, the use of herbal medicines for this purpose could be a good alternative to non-toxic treatments for curing some diseases (Tiptiri-Kourpeti et al., 2019), due to their fewer side effects among other reasons (Abdollahi et al., 2014; Lietava et al., 2019). One of these herbs is Cornelian cherry. Its scientific name is Cornus mas-land and it belongs to the genus Cornaceae. Its fruits are rich in anthocyanins such as cyanidin, peonidin, pelargonidin, and petunidin, and also contain bioflavonoids, vitamin $\mathrm{C}$, and ursolic acid. The anthocyanins lead to increased insulin secretion (pelargonidin increases insulin secretion up to 1.4 times), amelioration of insulin resistance, and improvement of hyperlipidemia (Dayar et al., 2020). Cornuse mas is used in Chinese and Iranian traditional medicine to treat diabetes and high blood lipids and their complications (Abdollahi et al., 2014; Lietava et al., 2019). 
Due to all the aforementioned facts, the purpose of the present study was to explore the effects of physical exercise (aerobic and resistance training), intake of Cornuse mas, and their combination on the lipid profile (triglycerides, HDL, low-density lipoprotein [LDL], cholesterol), metabolic parameters (glucose, creatinine, creactive protein [CRP], urea), and liver enzymes (ALT, AST) in obese male rats. We hypothesized that the combination of physical exercise and Cornuse mas extract will improve to a greater extent the assessed parameters, with no big difference between the aerobic and resistance exercise.

\section{MATERIAL AND METHODS}

\section{Participants}

49 male Wistar rats (age: six weeks; average weight: $200 \mathrm{~g}$ ) were randomly assigned to seven experimental groups: [1] control $(n=7)$ following a normocaloric diet and no treatment; [2] hypercaloric $(n=7)$ following a high-fat diet and no treatment; [3] aerobic exercise ( $A E, n=7)$; [4] resistance exercise $(R E, n=7)$; [5] Cornus mas extract intake $(C, n=7)$ following no exercise program; [6] Cornus mas extract intake in combination with aerobic exercise (CAE, $n=7)$; [7] Cornus mas extract intake in combination with resistance exercise (CRE, $n=7)$. All the groups were homogeneous in terms of number, breed, age, and weight. All ethical considerations and working protocols of this study were approved by Shahrekord's committee for monitoring Laboratory Animal Rights in Medical Sciences University with code 2-1-94.

The rats were kept for 12 weeks in the Shahrekord University Animal Laboratory Medical Sciences at a temperature between 22 and $27^{\circ} \mathrm{C}$. The room was illuminated in a controlled manner (12 hours off and 12 hours on). Six weeks were used to induce the fatty liver in the rats and six weeks to carry out the intervention. The hypercaloric, AE, RE, C, CAE, and CRE groups $(n=42)$ were induced with hyperlipidemia and hypercholesterolemia by diet (see below "Diet formulation" section) and 7 rats remained healthy following a normocaloric diet (controls).

\section{Intervention}

Diet formulation

During the six weeks before the intervention, the selected 42 rats were daily fed by gavage with a specific diet to induce hyperlipidemia and hypercholesterolemia. More concretely, Persintra-M was prepared from egg yolk to induce hyperlipidemia ( $1 \mathrm{~g}$ of cholesterol, palm oil of $80 \%$ purity, and intralipid fluid per $100 \mathrm{~g}$ of egg yolk) and $25 \mathrm{mg}$ of cholesterol were condensed to $2 \mathrm{ml}$ to induce hypercholesterolemia. In addition, the rat's meal was brought to $1 \%$ cholesterol and $20 \%$ sugar using palm oil, sugar, and cow fat.

During the intervention period (six weeks) only the hypercaloric group continued with the above explained hypercaloric diet and the rest of the groups switched to a normocaloric animal diet. The controls remained all the 12 weeks with a normocaloric diet. Water and food was freely available to all the rats throughout the study.

\section{Aerobic training program}

The six-week (three sessions per week) aerobic training program was performed on a treadmill and was divided into three phases (two weeks of adaptation, two weeks of overload, and two weeks of maintenance/consolidation). A familiarization period was carried out before the aerobic training program (see Table 1) to familiarize the rats with the materials and the procedures. All the phases used no inclination $\left(0^{\circ}\right)$. A 5-minute walk at $10 \mathrm{~m} / \mathrm{min}$ was used as a warm-up and cool-down in every session. The control group walked five minutes once per week at $10 \mathrm{~m} / \mathrm{min}$ and $0^{\circ}$ during the six weeks of the intervention. 
To stimulate the rats to walk, an auditory stimulus (tapping on the wall of the treadmill) was used. For this purpose, a low-voltage electrical stimulus was initially used together with an audio stimulus. After the rats were conditioned to two stimuli simultaneously, the single audio stimulus was used in later sessions to comply with the ethics of animal experimentation.

Table 1. Aerobic training program.

\begin{tabular}{|c|c|c|c|c|c|c|}
\hline & \multicolumn{2}{|c|}{ Adaptation phase } & \multicolumn{2}{|c|}{ Overload phase } & \multicolumn{2}{|c|}{ Maintenance phase } \\
\hline & First week & Second week & Third week & Fourth week & Fifth week & Sixth week \\
\hline $\begin{array}{l}\text { Speed } \\
\text { Time }\end{array}$ & $\begin{array}{c}8 \mathrm{~m} / \mathrm{min} \\
10 \mathrm{~min}\end{array}$ & $\begin{array}{c}12 \mathrm{~m} / \mathrm{min} \\
20 \mathrm{~min}\end{array}$ & $\begin{array}{c}18 \mathrm{~m} / \mathrm{min} \\
30 \mathrm{~min}\end{array}$ & $\begin{array}{c}20 \mathrm{~m} / \mathrm{min} \\
40 \mathrm{~min}\end{array}$ & $\begin{array}{c}20 \mathrm{~m} / \mathrm{min} \\
40 \mathrm{~min}\end{array}$ & $\begin{array}{c}20 \mathrm{~m} / \mathrm{min} \\
40 \mathrm{~min}\end{array}$ \\
\hline
\end{tabular}

Resistance training program

A one-meter ladder with 50 steps separated by $2 \mathrm{~cm}$, a width of $50 \mathrm{~cm}$, and an inclination of $85^{\circ}$ was used for the resistance training. A load pouch attached to the proximal portion of the rats' tail $(1-2 \mathrm{~cm}$ after the hair growth point) was used as resistance. Prior to the six weeks of the resistance training program, a familiarization period without external weight was carried out. The number of repetitions of the training program (see Table 2) in each session ranged from 8 to 12 repetitions, with a two-minute rest in between; each repetition had to be completed in 8 seconds. At the beginning and end of the exercise, 5 repetitions without weight were used as warm-up and cool-down. The rats were placed at the bottom of the ladder and were motivated to climb the ladder by gently pushing on their backside. No rewards or abnormal stimuli such as electrical stimulation, cold water, or air pressure were used in this study.

Table 2. Resistance training program.

\begin{tabular}{lcccccc}
\hline & \multicolumn{2}{c}{ Adaptation phase } & \multicolumn{2}{c}{ Overload phase } & \multicolumn{2}{c}{ Maintenance phase } \\
\hline & First & Second & Third & Fourth & Fifth & Sixth \\
& week & week & week & week & week & week \\
\hline Rats' weight average & $240 \mathrm{~g}$ & $252 \mathrm{~g}$ & $260 \mathrm{~g}$ & $266 \mathrm{~g}$ & $277 \mathrm{~g}$ & $287 \mathrm{~g}$ \\
$\begin{array}{l}\text { Ratio overload per } \\
\text { bodyweight }\end{array}$ & $50 \%$ & $75 \%$ & $85 \%$ & $95 \%$ & $110 \%$ & $120 \%$ \\
Average weight used & $120 \mathrm{~g}$ & $189 \mathrm{~g}$ & $221 \mathrm{~g}$ & $253 \mathrm{~g}$ & $305 \mathrm{~g}$ & $344 \mathrm{~g}$ \\
\hline
\end{tabular}

\section{Cornus mas extraction and use}

Samples of Cornus mas were procured from reputable suppliers and used after confirmation from the Center for Herbal Medicine Research of the University. The plant was pulverized using a mechanical mill (Moulinex, Osaka, Japan) and dissolved in 2 litres of alcohol (70\%) and water (30\%). The solution was left to stand for $72 \mathrm{~h}$ at laboratory temperature. It was then filtered and condensed in a rotary apparatus and kept in an incubator at a temperature of $37^{\circ} \mathrm{C}$ for three days. A dosage of $400 \mathrm{mg}$ of Cornus mas per one kilogram of body weight was administered daily to the rats by gavage.

\section{Measures}

After the six-week intervention, another session was used to extract the blood samples. The rats were anesthetized by an intraperitoneal injection of ketamine $(70 \mathrm{mg} / \mathrm{kg})$ and xylazine $(3-5 \mathrm{mg} / \mathrm{kg})$. Blood samples were taken from their hearts and were introduced in a Sigma centrifuge (Rontgen Co., Remscheid, Germany) at 5000 revolutions. At this point, the serum was transferred using Pars Azmoon kits (Pars Azmoon Co., Tehran, Iran) to a BT3000 analyser (Biotecnica Instrument S.p.A., Rome, Italy). Values of the lipid profile (triglycerides, HDL, LDL, cholesterol), metabolic parameters (glucose, creatinine, CRP, urea), and liver enzymes (ALT, AST) were calculated. 


\section{Data analysis}

After a basic data curation, the normality of the distribution and homogeneity of variances of each variable was assessed through the Shapiro-Wilk and Levene tests, respectively. Only the triglycerides complied with normality and homoscedasticity assumption among the seven groups. Therefore, a one-way analysis of variance (ANOVA) for the triglycerides and Kruskal Wallis testing for the non-normally distributed variables were conducted. The effect size was reported as the eta squared $\left(\eta^{2}\right)$ where $0.01<\eta^{2}<0.06$ constitutes a small effect, $0.06 \leq \eta^{2} \leq 0.14$ a medium effect and $\eta^{2}>0.14$ constitutes a large effect. After this, paired posthoc tests with Tukey adjustments for the parametric analysis and with no adjustment for the non-parametric evaluated significant differences. A 95\% confidence level (significance $p<.05$ ) was accepted as statistically significant. Statistical analysis was carried out using commercial software IBM SPSS Statistics for Macintosh (Version 26.0; IBM Corp., Armonk, NY). All data are reported as the means \pm the standard deviations and the $95 \%$ confidence interval.

\section{RESULTS}

Twelve weeks of fatty food diet were enough to significantly worsen almost all the variables in the hypercaloric group compared to the controls. The ANOVA and the Kruskal Wallis test indicated that significant differences existed among the study variables, with AST: $H(6)=29.01, p<.001, \eta^{2}=0.55 ; A L T: H(6)=18.09, p=.006$, $\eta^{2}=0.29$; CRP: $H(6)=24.20, p<.001, \eta^{2}=0.43$; creatinine: $H(6)=35.29, p<.001, \eta^{2}=0.70 ;$ urea: $H(6)$ $=31.57, p<.001, \eta^{2}=0.61$; cholesterol: $H(6)=34.13, p<.001, \eta^{2}=0.67$; glucose: $H(6)=21.58, p=.001$, $\eta^{2}=0.37$; triglycerides: $F(6)=14.78, p<.001, \eta^{2}=0.68$; LDL: $H(6)=24.84, p<.001, \eta^{2}=0.45$ and HDL: $H(6)=13.33, p=.038, \eta^{2}=0.18$. Tables 3 and 4 present the outcomes of the intervention in the liver enzymes and metabolic parameters.

\section{DISCUSSION}

This study aimed to assess the effectiveness of physical exercise (aerobic and resistance) and Cornus mas extract intake in improving blood parameters (lipid profile, liver enzymes, and metabolic parameters) of rats with fatty liver and obesity. For such purpose, a control group was kept healthy from the beginning and the other six groups were induced fatty liver and obesity by diet. Of these six groups, one continued having the hypercaloric diet and the other five joined different treatment programs (aerobic or resistance exercise, Cornus mas extract intake, and aerobic or resistance exercise combined with the intake of Cornuse mas extract). The most notable findings were that all the intervention groups after six weeks of treatment reverted their levels and significantly improved compared to the hypercaloric group in almost all the assessed parameters, reaching in many cases better values than the healthy group (control). These interesting results provide a strong foundation for the management and treatment of obesity and other associated conditions such as fatty liver, cardiovascular disease, metabolic syndrome, diabetes mellitus, atherosclerosis, and dyslipidemia (Dayar et al., 2020; El Hadi et al., 2019; Huang et al., 2009; Tomeno et al., 2020; Wong et al., 2016).

The outcomes presented are in accordance with previously published investigations that found improvements in different hepatic and lipidic parameters after intaking Cornuse mas extract both in rats (Alavian et al., 2014; Asgary et al., 2013, 2014) and humans with type 2 diabetes (Soltani et al., 2015). This beneficial effect of the Cornuse mas extract may be due to its content in antioxidants, phenolic compounds, and vitamins, which help in the prevention of inflammatory processes and oxidative stress associated with different metabolic and cardiovascular conditions (Abdollahi et al., 2014). What is new from this study, is the combination of the 
intake of Cornuse mas extract with aerobic and resistance exercises, which slightly improved (only significant for the cholesterol and glucose) the levels in almostall the variables compared to only performing the exercise programs or only intaking Cornuse mas extract.

Table 3. Levels of liver enzymes (AST/GOT and ALT/GPT) and metabolic parameters (CRP, creatinine, and urea) in all experimental groups (all $n=7$ ).

\begin{tabular}{|c|c|c|c|c|c|}
\hline Group & AST & ALT & CRP & Creatinine & Urea \\
\hline & $94.14 \pm 9.56^{2,4,6,7}$ & $39.71 \pm 6.77^{(3)}$ & $16.42 \pm 1.54$ & $0.72 \pm 0.04^{3,4,5,6,7}$ & $34.42 \pm 3.59^{*}$ \\
\hline 1 & [85.29-102.98] & [33.44-45.98] & [14.99-17.85] & {$[0.68-0.77]$} & [31.10-37.75] \\
\hline \multirow[t]{3}{*}{ (Control) } & Median: 97.00 & Median: 41.00 & Median: 17.00 & Median: 0.70 & Median: 34.00 \\
\hline & IQR: 15.00 & IQR: 11.00 & IQR: 0.80 & IQR: 0.10 & IQR: 7.00 \\
\hline & $161.00 \pm 25.60^{*}$ & $74.57 \pm 17.62^{1,4,4,6,6,7}$ & $23.15 \pm 0.79^{*}$ & $1.01 \pm 0.13^{3,4,5,6,7}$ & $60.85 \pm 15.29^{4,5,6,7}$ \\
\hline 2 & [137.46-184.82] & [58.27-9087] & [22.41-23.89] & [0.88-1.13] & [46.71-74.99] \\
\hline \multirow[t]{3}{*}{ (Hyper) } & Median: 150.00 & Median: 68.00 & Median: 23.20 & Median: 1.00 & Median: 53.00 \\
\hline & IQR: 45.00 & IQR: 20.00 & IQR: 0.80 & IQR: 0.10 & IQR:22.00 \\
\hline & $83.85 \pm 14.39(4)$ & $56.71 \pm 18.04^{(4), 7}$ & $17.04 \pm 1.27^{(5)}$ & $0.44 \pm 0.07$ & $48.71 \pm 2.62^{5,7}$ \\
\hline 3 & [70.54-97.16] & [40.02-73.40] & [15.85-18.22] & [0.37-0.51] & [46.28-51.14] \\
\hline \multirow[t]{3}{*}{$(\mathrm{AE})$} & Median: 86.00 & Median: 60.00 & Median: 17.20 & Median: 0.50 & Median: 49.00 \\
\hline & IQR: 24.00 & IQR: 34.00 & IQR: 3.00 & IQR: 0.10 & IQR: 4.00 \\
\hline & $65.85 \pm 11.82$ & $42.42 \pm 11.02$ & $17.24 \pm 0.975$ & $0.47 \pm 0.07$ & $45.28 \pm 4.27$ \\
\hline 4 & [54.92-76.79] & [32.22-52.62] & [16.34-18.14] & {$[0.40-0.54]$} & [41.33-49.23] \\
\hline \multirow{3}{*}{ (RE) } & Median: 66.00 & Median: 39.00 & Median: 16.80 & Median: 0.50 & Median: 45.00 \\
\hline & IQR: 29.00 & IQR: 8.00 & IQR: 1.30 & IQR: 0.10 & IQR: 9.00 \\
\hline & $79.57 \pm 19.90$ & $47.51 \pm 35.00$ & $15.61 \pm 0.93$ & $0.42 \pm 0.07$ & $42.85 \pm 3.18$ \\
\hline 5 & [61.16-97.98] & [32.61-62.41] & [14.75-16.47] & [0.35-0.49] & [39.91-45.80] \\
\hline \multirow[t]{3}{*}{ (C) } & Median: 88.00 & Median: 45.00 & Median: 15.80 & Median: 0.40 & Median: 42.00 \\
\hline & IQR: 23.00 & IQR: 35.00 & IQR: 1.60 & IQR: 0.00 & IQR: 4.00 \\
\hline & $71.42 \pm 14.03$ & $45.00 \pm 10.67$ & $16.12 \pm 1.73$ & $0.42 \pm 0.07$ & $47.14 \pm 6.54$ \\
\hline \multirow{4}{*}{$\begin{array}{c}6 \\
(\mathrm{CAE})\end{array}$} & [58.44-84.40] & [35.12-54.87] & [14.52-17.72] & [0.35-0.49] & [41.09-53.19] \\
\hline & Median: 79.00 & Median: 43.00 & Median: 16.20 & Median: 0.40 & Median: 47.00 \\
\hline & IQR: 29.00 & IQR: 24.00 & IQR: 3.00 & IQR: 0.10 & IQR: 8.00 \\
\hline & $63.57 \pm 22.04$ & $39.14 \pm 10.38$ & $15.47 \pm 1.76$ & $0.40 \pm 0.00$ & $42.71 \pm 3.45$ \\
\hline \multirow{3}{*}{$\begin{array}{c}7 \\
\text { (CRE) }\end{array}$} & [43.18-83.95] & [29.54-48.74] & [13.84-17.10] & [0.40-0.40] & [39.52-45.90] \\
\hline & Median: 61.00 & Median:39.00 & Median: 15.50 & Median: 0.40 & Median: 45.00 \\
\hline & IQR: 48.00 & R: 8.00 & & IQR: 00 & .00 \\
\hline
\end{tabular}

Data are presented as mean \pm standard deviation and $95 \%$ confidence interval for the mean [lower bound-upper bound]; median and interquartile range $(I Q R)$ are also displayed for the non-normal variables. Being *: significant difference $(p<.05)$ with all the rest of the groups; 1,2,3,4,5,6,7: significant difference with the group 1, 2, 3, 4, 5, 6, or 7, respectively (numbers between brackets represent statistical tendency at the level $0.5<p<1.3)$; IQR: interquartile range; Hyper: hypercaloric group; AE: aerobic exercise group; RE: resistance exercise group; C: Cornuse mas intake group; CAE: Cornuse mas intake in combination with aerobic exercise; CRE: Cornuse mas intake in combination with resistance exercise; AST: aspartate aminotransferase (also known as GOT); ALT: alanine aminotransferase (also known as GPT); CRP: C-reactive protein.

Regarding the effects of the exercise on the assessed parameters, a six-week program of both exercise methodologies was enough to improve the values of almost all the assessed variables, as happened in previous research (de Piano et al., 2012; Carbajo-Pescador et al., 2019; Slentz et al., 2011; Shamsoddini et al., 2015). On the other hand, one study reported inconsistent results in this regard (Barani et al., 2014). It is worth mentioning that resistance exercise showed trends of further improving liver enzymes and HDL than aerobic exercise. In fact, the six-week aerobic training program was not enough to significantly modify the $\mathrm{ALT}$, urea, and HDL levels. These positive results associated with the exercise could be due to its regulator 
effect on insulin resistance and glucose levels. In this regard, insulin resistance is associated with fatty liver and metabolic diseases. The main mechanisms of insulin resistance are negative regulation of deep insulin receptors and a decrease in signalling caused by excessive signalling of free fatty acids in the bloodstream (Akyüz et al., 2007). To perform muscle contractions during the exercise the levels of the glucose transporter type 4 protein, secondary messengers (Richter \& Hargreaves, 2013), and insulin-1 receptors rise to increase glucose uptake in the skeletal muscle (Chibalin et al., 2000). As a result, glucose is better absorbed, and insulin resistance is reduced. Furthermore, visceral fat represents a source of free fatty acids that can be preferentially oxidized to glucose. Reducing visceral fat by decreasing abdominal obesity may be another important benefit of exercise leading to significant improvement in metabolic indicators (Albright et al., 2000; Houttu et al., 2020). Due to all these aforementioned factors, we can state that physical exercise has a positive impact on the treatment of fatty liver and metabolic diseases.

Table 4. Levels of lipid profile in all experimental groups (all $n=7$ ).

\begin{tabular}{|c|c|c|c|c|c|}
\hline Group & Cholesterol & Glucose & Triglycerides & LDL & HDL \\
\hline & $47.28 \pm 9.12^{2,3,4,5,7}$ & $125.00 \pm 7.18^{2}$ & $64.00 \pm 18.61^{2,3,4,(5)}$ & $10.10 \pm 2.92^{*}$ & $37.97 \pm 6.00^{2,3}$ \\
\hline 1 & [38.84-55.72] & [118.35-131.64] & [46.78-81.21] & [7.39-12.81] & [32.41-43.52] \\
\hline (Control) & Median: 48.00 & Median: 126.00 & Median: 59.00 & Median: 9.70 & Median: 37.90 \\
\hline & IQR: 18.00 & IQR: 10.00 & IQR: 27.00 & IQR: 4.90 & IQR: 12.00 \\
\hline 2 & $\begin{array}{l}123.71 \pm 40.38^{(3), 4,6,7} \\
{[86.36-161.06]}\end{array}$ & $\begin{array}{l}216.85 \pm 29.65^{*} \\
{[189.43-244.27]}\end{array}$ & $\begin{array}{l}142.28 \pm 24.23^{*} \\
{[119.78-164.69]}\end{array}$ & $\begin{array}{l}39.05 \pm 5.29^{*} \\
{[34.15-43.95]}\end{array}$ & $\begin{array}{l}28.11 \pm 6.45^{4,(5), 7} \\
{[22.11-34.08]}\end{array}$ \\
\hline (Hyper) & Median: 108.00 & Median: 216 & Median: 139.00 & Median: 37.20 & Median: 30.50 \\
\hline & IQR: 71.00 & IQR: 57.00 & IQR: 47.00 & IQR: 9.30 & IQR: 12.30 \\
\hline & $81.85 \pm 5.45^{6}$ & $124.42 \pm 3.99$ & $97.57 \pm 15.45$ & $13.95 \pm 2.28$ & $31.84 \pm 3.20(4), 7$ \\
\hline 3 & [76.80-86.90] & [120.73-128.12] & [83.27-11.86] & [11.83-16.06] & [28.87-34.81] \\
\hline$(\mathrm{AE})$ & Median: 80.00 & Median: 125.00 & Median: 99.00 & Median: 14.20 & Median: 31.40 \\
\hline & IQR: 10.00 & IQR: 7.00 & IQR: 21.00 & IQR: 2.80 & IQR: 3.70 \\
\hline & $79.42 \pm 2.22$ & $125.00 \pm 8.56$ & $93.00 \pm 21.97$ & $14.94 \pm 2.73$ & $35.81 \pm 3.91$ \\
\hline 4 & [77.37-81.48] & [117.08-132.91] & [72.67-113.32] & [12.41-17.47] & [32.19-39.43] \\
\hline (RE) & Median: 79.00 & Median: 125.00 & Median: 91.00 & Median: 15.20 & Median: 36.30 \\
\hline & IQR: 3.00 & IQR: 11.00 & IQR: 37.00 & IQR: 4.50 & IQR: 2.50 \\
\hline & $85.57 \pm 8.99^{6}$ & $132.42 \pm 12.24(6),(7)$ & $89.71 \pm 10.45$ & $14.06 \pm 4.12$ & $35.05 \pm 4.48$ \\
\hline 5 & [77.25-93.89] & [121.10-143.75] & [80.04-99.38] & [10.24-17.88] & [30.90-39.20] \\
\hline (C) & $\begin{array}{l}\text { Median: } 85.00 \\
\text { IQR: } 9.00\end{array}$ & $\begin{array}{l}\text { Median: } 131.00 \\
\text { IQR: } 21.00\end{array}$ & $\begin{array}{l}\text { Median: } 87.00 \\
\text { IQR: } 16.00\end{array}$ & $\begin{array}{l}\text { Median: } 11.40 \\
\text { IQR: } 7.00\end{array}$ & $\begin{array}{l}\text { Median: } 36.20 \\
\text { IQR: } 9.70\end{array}$ \\
\hline 6 & $\begin{array}{l}70.00 \pm 6.75 \\
{[63.75-76.24]}\end{array}$ & $\begin{array}{l}119.28 \pm 10.30 \\
{[109.75-128.81]}\end{array}$ & $\begin{array}{l}73.85 \pm 10.33 \\
{[64.29-83.41]}\end{array}$ & $\begin{array}{l}13.76 \pm 2.42 \\
{[11.52-16.00]}\end{array}$ & $\begin{array}{l}34.52 \pm 6.84 \\
{[28.19-40.85]}\end{array}$ \\
\hline (CAE) & Median: 70.00 & Median: 121.00 & Median: 73.00 & Median: 14.20 & Median: 30.80 \\
\hline & IQR: 11.00 & IQR: 19.00 & IQR: 18.00 & IQR: 4.70 & IQR: 8.90 \\
\hline & $78.42 \pm 6.80$ & $121.85 \pm 5.61$ & $78.85 \pm 15.98$ & $13.87 \pm 2.14$ & $37.92 \pm 4.54$ \\
\hline 7 & [72.13-84.72] & [116.66-127.04] & [64.07-93.63] & [11.89-15.86] & [33.72-42.13] \\
\hline (CRE) & $\begin{array}{l}\text { Median: } 81.00 \\
\text { LR. } 12 \text {.00 }\end{array}$ & Median: 123.00 & $\begin{array}{l}\text { Median: } 81.00 \\
\text { LR. } 2800\end{array}$ & $\begin{array}{l}\text { Median: } 12.80 \\
\text { IOR. } 4.30\end{array}$ & $\begin{array}{l}\text { Median: } 36.50 \\
\text { IOR. } 600\end{array}$ \\
\hline
\end{tabular}

Data are presented as mean \pm standard deviation and $95 \%$ confidence interval for the mean [lower bound-upper bound]; median and interquartile range (IQR) are also displayed for the non-normal variables. Being *: significant difference $(p<.05)$ with all the rest of the groups; 1,2,3,4,5,6,7: significant difference with the group 1,2, 3, 4, 5, 6, or 7, respectively (numbers between brackets represent statistical tendency at the level $0.5<p<1.3$ ); IQR: interquartile range; Hyper: hypercaloric group; AE: aerobic exercise group; RE: resistance exercise group; C: Cornuse mas intake group; CAE: Cornuse mas intake in combination with aerobic exercise; CRE: Cornuse mas intake in combination with resistance exercise; LDL: low-density lipoprotein; HDL: high-density lipoprotein. 


\section{CONCLUSION}

According to the results of this study, Cornus Mas extract intake in combination with aerobic or resistance training may be recommended to improve fatty liver and obesity by improving the blood lipid profile, metabolic parameters, and liver enzyme levels. Therefore, the Cornuse mas extract and the exercise may be a good alternative or adjuvant to the use of chemical medicine.

\section{ACKNOWLEDGMENTS}

The authors gratefully acknowledge the cooperation of the Shahrekord Medicinal Plants Research Center, which supported and funded this project. We would also like to thank all the research staff members who participated in the present study.

\section{REFERENCES}

Abdollahi, B., Mesgari Abbasi, M., Zakeri Milani, P., Nourdadgar, A. S., Banan Khojasteh, S. M., \& Nejati, V. (2014). Hydro-methanolic extract of Cornus mas L. and blood glucose, lipid profile, and hematological parameters of male rats. Iranian Red Crescent Medical Journal, 16(5), e17784. https://doi.org/10.5812/ircmj.17784

Akyüz, F., Demir, K., Özdil, S., et al. (2007). The effects of rosiglitazone, metformin, and diet with exercise in nonalcoholic fatty liver disease. Digestive Diseases and Sciences, 52, 2359-2367 https://doi.org/10.1007/s10620-006-9145-x

Alavian, S., Banihabib, N., Es Haghi, M., \& Panahi, F. (2014). Protective effect of Cornus mas fruit extract on serum biomarkers in CCl4-induced hepatotoxicity in male rats. Hepatitis Monthly, 14(4), e10330. https://doi.org/10.5812/hepatmon.10330

Albright, A., Franz, M., Hornsby, G., Kiriska, A., Marrero, D., Urlich, I., \& Verity, L. S. (2000). Exercise and type diabetes. Medicine and Science in Sport and Exercise, 32, 1345-1360. https://doi.org/10.1097/00005768-200007000-00024

Asgary, S., Kelishadi, R., Rafieian-Kopaei, M., Najafi, S., Najafi, M., \& Sahebkar, A. (2013). Investigation of the lipid-modifying and antiinflammatory effects of Cornus mas $L$. supplementation on dyslipidemic children and adolescents. Pediatric Cardiology, 34(7), 1729-1735. https://doi.org/10.1007/s00246$\underline{013-0693-5}$

Asgary, S., Rafieian-Kopaei, M., Shamsi, F., Najafi, S., \& Sahebkar, A. (2014). Biochemical and histopathological study of the anti-hyperglycemic and anti-hyperlipidemic effects of Cornelian cherry (Cornus mas $L$ ) in alloxan-induced diabetic rats. Journal of Complementary and Integrative Medicine, 11(2), 63-69. https://doi.org/10.1515/jcim-2013-0022

Barani F., Afzalpour M. E., llbiegi S., Kazemi T., \& Mohammadi Fard M. (2014). The effect of resistance and combined exercise on serum levels of liver enzymes and fitness indicators in women with nonalcoholic fatty liver disease. Journal of Birjand University of Medical Science, 21(2),188-202. http://journal.bums.ac.ir/article-1-1588-en.html

Carbajo-Pescador, S., Porras, D., García-Mediavilla, M. V., et al. (2019). Beneficial effects of exercise on gut microbiota functionality and barrier integrity, and gut-liver crosstalk in an in vivo model of early obesity and non-alcoholic fatty liver disease. Disease Models \& Mechanisms, 12, dmm039206. https://doi.org/10.1242/dmm.039206

Chibalin, A. V., Yu, M., Ryder, J. W., Song, X. M., Galuska, D., Krook, A., Wallberg-Henriksson, H., \& Zierath, J. R. (2000). Exercise-induced changes in expression and activity of proteins involved in insulin signal transduction in skeletal muscle: differential effects on insulin-receptor substrates 1 and 
2. Proceedings of the National Academy of Sciences of the United States of America, 97(1), 38-43. https://doi.org/10.1073/pnas.97.1.38

Dayar, E., Cebova, M., Lietava, J., Panghyova, E., \& Pechanova, O. (2020). Beneficial effects of cornelian cherries on lipid profile and no/ros balance in obese zucker rats: Comparison with CoQ10. Molecules (Basel, Switzerland), 25(8), 1922. https://doi.org/10.3390/molecules25081922

de Piano, A., de Mello, M. T., Sanches, P., et al. (2012). Long-term effects of aerobic plus resistance training on the adipokines and neuropeptides in nonalcoholic fatty liver disease obese adolescents. European Journal of Gastroenterology \& Hepatology, 24(11), 1313-1324. https://doi.org/10.1097/MEG.0b013e32835793ac

Della Pepa, G., Vetrani, C., Lombardi, G., Bozzetto, L., Annuzzi, G., \& Rivellese, A. (2017). Isocaloric dietary changes and non-alcoholic fatty liver disease in high cardiometabolic risk individuals. Nutrients, 9(10), 1065. https://doi.org/10.3390/nu9101065

Dunstan, D. W., Daly, R. M., Owen, N., Jolley, D., de Courten, M., Shaw, J., \& Zimmet, P. (2001). High intensity resistance training improves glycemic control in older patients with type 2 diabetes. Diabetes Care, 25, 1729-1736. https://doi.org/10.2337/diacare.25.10.1729

El Hadi, H., Di Vincenzo, A., Vettor, R., \& Rossato, M. (2019). Cardio-metabolic disorders in non-alcoholic fatty liver disease. International Journal of Molecular Sciences, 20(9), 2215. https://doi.org/10.3390/ijms20092215

Hallsworth K., Fattakhova G., Hollingsworth K. G., et al. (2011). Resistance exercise reduces liver fat and its mediators in non-alcoholic fatty liver disease independent of weight loss. Gut, 60, 1278-1283. https://doi.org/10.1136/gut.2011.242073

Houttu, V., Boulund, U., Grefhorst, A., Soeters, M. R., Pinto-Sietsma, S. J., Nieuwdorp, M., \& Holleboom, A. G. (2020). The role of the gut microbiome and exercise in non-alcoholic fatty liver disease. Therapeutic Advances in Gastroenterology, 13, 1-21. https://doi.org/10.1177/1756284820941745

Huang, P.L. (2009). eNOS, metabolic syndrome and cardiovascular disease. Trends in Endocrinology \& Metabolism, 20, 295-302 https://doi.org/10.1016/j.tem.2009.03.005

Huang, X. J., Choi, Y. K., Im, H. S., Yarimaga, O., Yoon, E., \& Kim, H. S. (2006). Aspartate aminotransferase (AST/GOT) and alanine aminotransferase (ALT/GPT) detection techniques. Sensors (Basel, Switzerland), 6(7), 756-782. https://doi.org/10.3390/s6070756

Iloon Kashkooli, R., Najafi, S. S., Sharif, F., Hamedi, A., Hoseini Asl, M. K., Najafi Kalyani, M., \& Birjandi, M. (2015) The effect of berberis vulgaris extract on transaminase activities in non-alcoholic fatty liver disease. Hepatitis Monthly, 15(2):e25067. https://doi.org/10.5812/hepatmon.25067

Ismaiel, A., \& Dumitraşcu, D. L. (2019). Cardiovascular risk in fatty liver disease: the liver-heart axisliterature review. Frontiers in Medicine, 6, 202. https://doi.org/10.3389/fmed.2019.00202

Lehto, S., Rönnemaa, T., Haffher, S. M., Pyörälä, K., Kallio, V., \& Laakso, M. (1997). Dyslipidemia and hyperglycemia predict coronary heart disease events in middle-aged patients with NIDDM. Diabetes, 46(8), 1354-1359. https://doi.org/10.2337/diab.46.8.1354

Lietava, J., Beerova, N., Klymenko, S. V., Panghyova, E., Varga, I., \& Pechanova, O. (2019). Effects of cornelian cherry on atherosclerosis and its risk factors. Oxidative Medicine and Cellular Longevity, 2019, 1-8. https://doi.org/10.1155/2019/2515270

Nikroo, H., Attarzade Hosseini, S., Sima H., \& Nematy, M. (2011). The effect of diet and aerobic training on serum aminotransferases levels in patients with non-alcoholic steatohepatitis. Journal of Daneshvar Medicine, 93, 51-60.

Reid, A. (2006). Nonalcoholic steatohepatitis. Gastroenterology, 121(3), 710-723. https://doi.org/10.1053/gast.2001.27126

Richter, E. A., \& Hargreaves M. (2013). Exercise, GLUT4, and skeletal muscle glucose uptake. Physiological Reviews, 93, 993-1017. https://doi.org/10.1152/physrev.00038.2012 
Shamsoddini, A., Sobhani, V., Ghamar Chehreh, M. E., Alavian, S. M., \& Zaree, A. (2015). Effect of aerobic and resistance exercise training on liver enzymes and hepatic fat in Iranian men with nonalcoholic fatty liver disease. Hepatitis Monthly, 15(10), e31434. https://doi.org/10.5812/hepatmon.31434

Slentz, C. A., Bateman, L. A., Willis, L. H., et al. (2011). Effects of aerobic vs. resistance training on visceral and liver fat stores, liver enzymes, and insulin resistance by HOMA in overweight adults from STRRIDE AT/RT. American Journal of Physiology, Endocrinology, and Metabolism, 301(5), e1033e1039. https://doi.org/10.1152/ajpendo.00291.2011

Soltani, R., Gorji, A., Asgary, S., Sarrafzadegan, N., \& Siavash, M. (2015). Evaluation of the effects of Cornus mas $L$ fruit extract on glycemic control and insulin level in type 2 diabetic adult patients: a randomized double-blind placebo-controlled clinical trial. Evidence-Based Complementary and Alternative Medicine, 740954. https://doi.org/10.1155/2015/740954

Stevanović, J., Beleza, J., Coxito, P., Ascensão, A., \& Magalhães, J. (2020). Physical exercise and liver "fitness": Role of mitochondrial function and epigenetics-related mechanisms in non-alcoholic fatty liver disease. Molecular Metabolism, 32, 1-14. https://doi.org/10.1016/j.molmet.2019.11.015

Thompson, D. P. \& Rader, J. D. (2001). Does exercise increase HDL cholesterol in those who need it the most? Arteriosclerosis, Thrombosis, and Vascular Biology, 21(7), 1097-1098. https://doi.org/10.1161/hq0701.092147

Tiptiri-Kourpeti, A., Fitsiou, E., Spyridopoulou, K., Vasileiadis, S., lliopoulos, C., Galanis, A., Vekiari, S., Pappa, A., \& Chlichlia, K. (2019). Evaluation of antioxidant and antiproliferative properties of Cornus mas L. fruit juice. Antioxidants, 8(9), 377. https://doi.org/10.3390/antiox8090377

Tomeno, W., Imajo, K., Takayanagi, T., et al. (2020). Complications of non-alcoholic fatty liver disease $\begin{array}{llll}\text { in extrahepatic organs. Diagnostics } & \text { (Basel), } & 10(11), & \end{array}$ https://doi.org/10.3390/diagnostics10110912

Wong, S. K., Chin, K. Y., Suh, F. H. Fairus, A., \& Ima-Nirwana, S. (2016). Animal models of metabolic syndrome: a review. Nutrition and Metabolism (London), 13, 65. https://doi.org/10.1186/s12986-016$\underline{0123-9}$

Yavari, A., Najafipoor, F., Aliasgharzadeh, A., Niafar, M., \& Mobasseri, M. (2012). Effect of aerobic exercise, resistance training, or combined training on glycaemic control and cardiovascular risk factors in patients with type 2 diabetes. Biology of Sport, 29(2), 135-143. https://doi.org/10.5604/20831862.990466

Yıldırım, N. C., Yürekli, M., \& Yıldırım, N. (2010). Soğuk Stresi ve Adrenomedullin Uygulamasına Bağlı Olarak Sıçan Karaciğer Dokusunda Bazı Antioksidan Enzim Aktivitelerinin Araștııılması [Investigation of some antioxidant enzymes activities depending on adrenomedullin treatment and cold stress in rat liver tissue]. Türk Biyokimya Dergisi [Turkish Journal of Biochemistry], 35(2),140-4. https://citeseerx.ist.psu.edu/viewdoc/download?doi=10.1.1.631.7467\&rep=rep1\&type=pdf

Zelber-Sagi, S., Ratziu, V., \& Oren, R. (2011). Nutrition and physical activity in NAFLD. An overview of the epidemiological evidence. World Journal of Gastroenterology, 17(29), 3377-3389. https://doi.org/10.3748/wjg.v17.i29.3377

\section{(9) $\odot \Theta \Theta$}

This work is licensed under a Attribution-NonCommercial-NoDerivatives 4.0 International (CC BY-NC-ND 4.0). 